\title{
Comment on 'High MET expression is an adverse prognostic factor in patients with triple-negative breast cancer'
}

\author{
C Ho-Yen ${ }^{*}, 1, \mathrm{R} L$ Bowen $^{2}$, S Kermorgant ${ }^{1}$ and J L Jones ${ }^{1}$ \\ ${ }^{1}$ Centre for Tumour Biology, Barts Cancer Institute, Queen Mary University of London, London, UK and ${ }^{2}$ Department of Oncology, \\ Royal United Hospital, Bath, UK
}

Sir,

In their recent article, Zagouri et al (2013) show that high c-Met expression is associated with a worse outcome in triple-negative (TN) breast cancer, however the authors state that they 'did not include further markers such as basal cytokeratins and/or EGFR that may identify a group of tumours that have a distinct adverse prognosis'. This is a surprising omission, as data from several studies indicate that TN tumours that express basal markers are distinct from those that do not, and that these 'Core Basal' tumours have a worse outcome (Blows et al, 2010). Whether c-Met contributes to this poorer prognosis would therefore appear to be an important question to address.

In our own immunohistochemical (IHC) analysis, we identified $38 \mathrm{TN}$ tumours from a cohort of 182 patients with invasive breast cancer. We divided the TN group into 'Core Basal' ( $\mathrm{CB}, n=31)$ and basal marker negative (referred to as 'Unclassified' (U), $n=7$ ) using a panel of antibodies to basal markers (Rakha et al, 2009; Blows et al, 2010): CK5/6, CK14, CK17 and EGFR (with a cut-off of $10 \%$ tumour reactivity to denote positivity). Positivity for any of the basal markers placed the tumour in the $\mathrm{CB}$ group. The sections were stained for c-Met (CVD13, Invitrogen) and the staining was scored semi-quantitatively (0-3 for intensity and 0-4 for area of tumour reactivity to give a sum score of $0-7)$. Both the cytoplasmic and membranous scores were combined to give a total c-Met score between 0 and 14. Analysing c-Met expression as a continuous variable (Figure 1), CB tumours had a significantly higher median total c-Met score of 8.4 (interquartile range $(\mathrm{IQR})=7.0-10.3)$ compared with 6.0 (IQR = 5.7-7.0) for $\mathrm{U}$ tumours (Mann-Whitney test, $P=0.008$ ). By comparison, it is very possible that the high c-Met expressing tumours in the study by Zagouri et al (2013) were predominantly $\mathrm{CB}$ tumours, and this raises the possibility that patients with $\mathrm{CB}$ tumours may derive more benefit from anti-c-Met therapy.

Knowledge of EGFR status may be of further clinical relevance. There is growing evidence that c-Met and EGFR can crosstalk in a variety of cancers (Lai et al, 2009). Amplification of the MET gene has been described in Gefitinib/Erlotinib-resistant non-small-cell

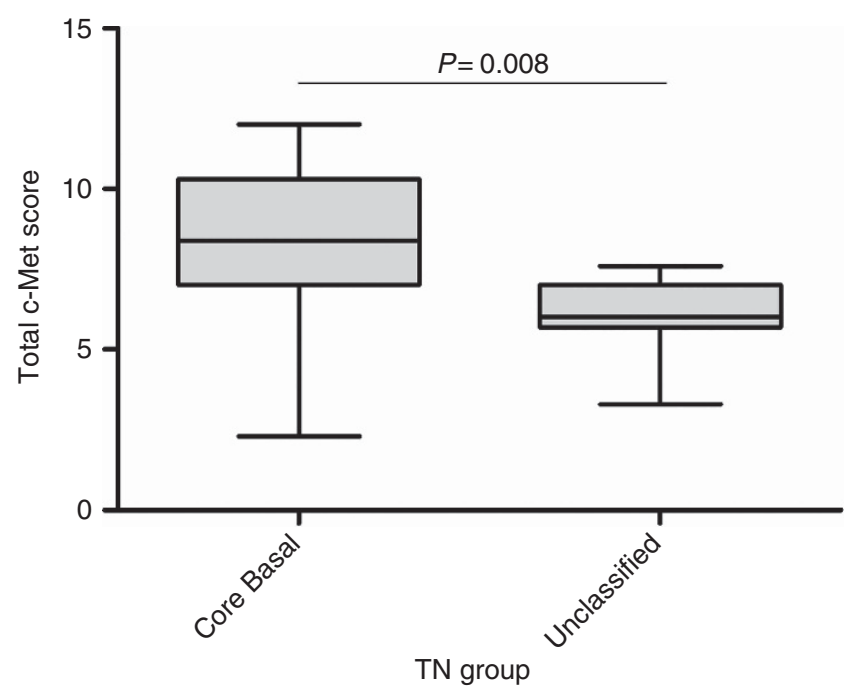

Figure 1. Box plot showing total c-Met scores for the Core Basal and Unclassified groups of TN tumours. The whiskers represent the minimum and maximum values (Mann-Whitney test, $P=0.008$ ).

lung cancer (NSCLC) cell lines, leading to persistent signalling via the PI3K pathway (Bean et al, 2007; Engelman et al, 2007). Moreover, treatment with a combination of a c-Met tyrosine kinase inhibitor (PHA-665752) and Gefitinib resulted in reduced PI3K/AKT signalling and growth inhibition in Gefitinib-resistant NSCLC cells (Engelman et al, 2007). Similarly, in the presence of Gefitinib, EGFR phosphorylation in the breast cancer cell line SUM229 has been shown to be mediated by a c-Met/c-Src-dependant pathway (Mueller et al, 2008). These studies suggest that c-Met and EGFR have a compensatory relationship, whereby inhibition of one receptor tyrosine kinase 
(RTK) may result in the activation of the other, thus maintaining downstream signalling (Lai et al, 2009). In our own analysis, we found a positive correlation between c-Met and EGFR expression (Spearman's correlation coefficient $=0.290, P<0.001$ ), indicating that compensation may be possible in these tumours. While several of the c-Met kinase inhibitors currently in clinical trials have activity against multiple RTKs, it would seem appropriate to consider EGFR expression (and other RTKs) when investigating the clinical significance of c-Met; these data would be of clear benefit in clinical trial design and patient selection.

In summary, the study by Zagouri et al (2013) provides further evidence of the involvement of c-Met in breast cancer progression, but the clinical impact of the study would have been enhanced by addressing the expression of basal markers, including EGFR, and this further supports the recognition of $\mathrm{CB}$ tumours as a distinct subset of TN cancers.

\section{REFERENCES}

Bean J, Brennan C, Shih JY, Riely G, Viale A, Wang L, Chitale D, Motoi N, Szoke J, Broderick S, Balak M, Chang WC, Yu CJ, Gazdar A, Pass H, Rusch V, Gerald W, Huang SF, Yang PC, Miller V, Ladanyi M, Yang CH, Pao W (2007) MET amplification occurs with or without T790M mutations in EGFR mutant lung tumors with acquired resistance to gefitinib or erlotinib. Proc Natl Acad Sci USA 104(52): 20932-20937.

Blows FM, Driver KE, Schmidt MK, Broeks A, van Leeuwen FE, Wesseling J, Cheang MC, Gelmon K, Nielsen TO, Blomqvist C, Heikkilä P, Heikkinen
T, Nevanlinna H, Akslen LA, Bégin LR, Foulkes WD, Couch FJ, Wang X, Cafourek V, Olson JE, Baglietto L, Giles GG, Severi G, McLean CA, Southey MC, Rakha E, Green AR, Ellis IO, Sherman ME, Lissowska J, Anderson WF, Cox A, Cross SS, Reed MW, Provenzano E, Dawson SJ, Dunning AM, Humphreys M, Easton DF, García-Closas M, Caldas C, Pharoah PD, Huntsman D (2010) Subtyping of breast cancer by immunohistochemistry to investigate a relationship between subtype and short and long term survival: a collaborative analysis of data for 10,159 cases from 12 studies. PLoS Med 7(5): e1000279.

Engelman JA, Zejnullahu K, Mitsudomi T, Song Y, Hyland C, Park JO, Lindeman N, Gale CM, Zhao X, Christensen J, Kosaka T, Holmes AJ, Rogers AM, Cappuzzo F, Mok T, Lee C, Johnson BE, Cantley LC, Jänne PA (2007) MET amplification leads to gefitinib resistance in lung cancer by activating ERBB3 signaling. Science 316(5827): 1039-1043.

Lai AZ, Abella JV, Park M (2009) Crosstalk in Met receptor oncogenesis. Trends Cell Biol 19(10): 542-551.

Mueller KL, Hunter LA, Ethier SP, Boerner JL (2008) Met and c-Src cooperate to compensate for loss of epidermal growth factor receptor kinase activity in breast cancer cells. Cancer Res 68(9): 3314-3322.

Rakha EA, Elsheikh SE, Aleskandarany MA, Habashi HO, Green AR, Powe DG, El-Sayed ME, Benhasouna A, Brunet JS, Akslen LA, Evans AJ, Blamey R, Reis-Filho JS, Foulkes WD, Ellis IO (2009) Triple-negative breast cancer: distinguishing between basal and nonbasal subtypes. Clin Cancer Res 15(7): 2302-2310.

Zagouri F, Bago-Horvath Z, Rössler F, Brandstetter A, Bartsch R, Papadimitriou CA, Dimitrakakis C, Tsigginou A, Papaspyrou I, Giannos A, Dimopoulos MA, Filipits M (2013) High MET expression is an adverse prognostic factor in patients with triple-negative breast cancer. Br J Cancer 108(5): 1100-1105. 